\title{
Ventilator-Associated Pneumonia in an Adult Clinical-Surgical Intensive Care Unit of a Brazilian University Hospital: Incidence, Risk Factors, Etiology, and Antibiotic Resistance
}

Laura de Andrade da Rocha ${ }^{1}$, Carolina Assis Pereira Vilela ${ }^{1}$, Renata Cristina Cezário ${ }^{1}$, Alair Benedito Almeida ${ }^{2}$ and Paulo Gontijo Filho ${ }^{1}$

${ }^{1}$ Institute of Biomedical Science, Federal University of Uberlândia; ${ }^{2}$ Intensive Care Unit of Clinical Hospital of Federal University of Uberlândia; Uberlândia, MG, Brazil

\begin{abstract}
The objective of this study was to evaluate clinical characteristics, etiology, and resistance to antimicrobial agents, among patients with ventilator-associated pneumonia (VAP). A case study $v s$. patients control under mechanical ventilation and hospitalized into clinical-surgical adults ICU of HC-UFU was performed from March/2005 to March/ 2006. Patients under ventilation for over $48 \mathrm{~h}$ were included in the study including 84 with diagnosis of VAP, and 191 without VAP (control group). Laboratory diagnosis was carried out through quantitative microbiological evaluation of tracheal aspirate. The identification of pathogens was performed by classical microbiological tests, and the antibiotics sensitivity spectrum was determined through the CLSI technique. VAP incidence rate over 1,000 days of ventilation was 24.59 . The mean $( \pm$ SD) duration of mechanical ventilation prior to VAP diagnosis was $23.2 \pm 17.2$ days. By multivariate analysis the risk factors predisposing for VAP were: mechanical ventilation time and mechanical ventilation $\geq$ seven days, tracheostomy and use of $\geq$ three antibiotics. Mortality rate was high (32.1\%) but lower than that of the control group (46.5\%). Major pathogens were identified in most of patients $(95.2 \%)$ and included: Pseudomonas aeruginosa (29\%), Staphylococcus aureus (26\%), Enterobacter/Klebsiella/Serratia (19\%) and Acinetobacter spp. (18\%), with expressive frequencies of P. aeruginosa (52\%), S. aureus $(65.4 \%)$ and Enterobacteriaceae $(43.7 \%)$ resistant to imipenem, oxacillin and $3 / 4$ generation cephalosporins, respectively. In conclusion, our observation showed VAPs caused by multiresistant microorganisms, the prescription of $\geq$ three antibiotics, and mortality with unacceptably high rates. The practice of de-escalation therapy appears to be urgently needed in order to improve the situation.
\end{abstract}

Key-Words: Ventilator-associated pneumonia, intensive care unit (ICU), antibiotic resistance.

Pneumonia is the most common infection in the intensive care unit where it accounts for $31 \%$ and $47 \%$ of nosocomial infections in Europe and US hospitals, respectively [1,2]. The development of nosocomial pneumonia after $48 \mathrm{~h}$ or later among intubated and mechanically ventilated patients is known as ventilator-associated pneumonia (VAP) [3]. Hospitalacquired pneumonia (HAP) is the leading cause of mortality attributed to nosocomial infections [4]. Approximately $60 \%$ of all deaths in patients with nosocomial infections are associated with HAP/VAP, and the reported hospital mortality rates for HAP/VAP range from $20 \%$ to $70 \%$ [5]. Attributable mortality in patients with VAP can account for up to $50 \%$ of all deaths [6,7]. Additionally, the occurrence of VAP prolongs the duration of hospital stay by six to 30 days and incurs additional medical expenses ranging from $\$ 5,000$ to $\$ 40,000$ per case $[3,5,7]$.

The initial choice of antimicrobial regimen appears to be of critical importance in determining the eventual clinical outcomes in patients with VAP, particularly hospital mortality. Early, aggressive, empirical therapy with broad-spectrum agents targeted at likely pathogens has been associated with a reduction in VAP mortality rates [8-10], with significantly higher VAP-attributable mortality rate among patients with

Received on 20 August 2007; revised 29 January 2008.

Address for correspondence: Dr. Laura de Andrade da Rocha. Rua dos Lírios Azuis, 43, Cidade Jardim. Phone: (34) 3238-3497/Fax: (34) 3218-2333. E-mail: laurarocha10@yahoo.com.br.

Financial support: grant from Conselho Nacional de Pesquisa (CNPq), Brazil. (n ${ }^{\text {: }}$ B-017/2005 and B-013-2006).

The Brazilian Journal of Infectious Diseases 2008;12(1):80-85. (C) 2008 by The Brazilian Journal of Infectious Diseases and Contexto Publishing. All rights reserved. initially inadequate antimicrobial coverage compared with adequate empirical regimens $[9,10]$.

The concept of de-escalation therapy is emerging as an effective strategy for the management of VAP and other serious infections $[11,12]$. This concept entails the early implementation of broad-spectrum empirical coverage followed by a regimen driven by microbiological documentation. This strategy, while ensuring a high likelihood of adequate initial coverage, at the same time avoids the long-term use of unnecessary antibiotic, thereby minimizing resistance concerns [13] limiting the selective pressure of antimicrobial agents onward the microorganism [14].

There is evidence that rates of VAP are higher in countries with limited resources [15], although lack of specificity in the definition of pneumonia makes it difficult to be confident of this assertion. By the way, in contrast to US data, respiratory tract infections have been found to be the most frequent nosocomial infection in Brazil [16]. A major important barrier in the field of infection control is the rarity of microbiology support and/or the fact that the physicians lose confidence in microbiology data and as a consequence it is common to start antibiotics without even asking for specific cultures [16].

The objective of this study was to determine the incidence and risk factors for VAP, and to evaluate the pathogens associated and their resistance profile in ICU patients at a Brazilian university hospital.

Material and methods

Patients, Hospital and ICU

Uberlândia Federal University Hospital is a 500-bed teaching hospital. The hospital has an adult ICU with 15 beds 
for medical and surgical patients.

\section{Design}

A case-control study was performed. Two hundred and seventy-five patients were eligible for inclusion in the study (80 cases and 191 controls), meeting the following criteria: hospitalized, intubated and receiving mechanical ventilation $\geq 48$ hours, and $>15$ years of age, from March 2005 to March 2006.

\section{$\underline{\text { Definitions }}$}

Pneumonia was considered ventilator associated when its onset occurred after 48 hours of mechanical ventilation and it was diagnosed when new, persistent pulmonary infiltrates appeared on chest radiographs and, at least two of following criteria were also required: (1) fever of $\geq 38^{\circ} \mathrm{C}$, (2) leukocytosis of $10,000 \backslash \mathrm{mm}^{3}$ or greater, and (3) purulent respiratory secretions. In cases of clinically suspected pneumonia, endotracheal aspirate (EA) was performed early in the morning; and the diagnosis of VAP was established with a positive quantitative culture (cut-off point $\geq 10^{6} \mathrm{CFU} /$ $\mathrm{mL})$.

To analyze the predisposing factors for development of VAP, the following variables were evaluated: age, gender, underlying diseases (diabetes mellitus, COPD and infection on admission), diagnosis at hospitalization, total ICU stay, antibiotical and corticosteroid therapy, length of mechanical ventilation, tracheostomy, and presence of a central venous catheter.

\section{Statistical Analysis}

Univariate analysis was used to compare variables for the outcome groups of interest. Continuous variables were compared using Student's $t$ test for normally distributed variables. The $\chi^{2}$ statistic or Fisher's exact test was used to compare categorical variables. Multivariate analysis was performed using multiple logistic regression with stepwise approach for entering new terms into the BioEstat model with 0.05 as the limit for their acceptance or removal [17]. All pvalue lower than 0.05 were considered significant.

The study was approved by the UFU Ethical Committee because it required access to and use of protected information, but, as most of the eligible patients were sedated for mechanical ventilation and because of the purely observational nature of the study, informed consent was waived.

\section{Results}

During the study period, 275 patients were admitted to the ICU in mechanical ventilation. The VAP patients and control group demographics are shown in Table 1. Amongst all patients requiring MV, $84(30.5 \%)$ developed VAP, and $80(95.2 \%)$ of them had just one VAP episode with positive cultures.

Late onset VAP occurring after four days was found in 67 cases $(79.7 \%)$, while early onset VAP occurred in 17 cases $(20.3 \%)$. The device-related incidence rate for VAP was 24.59 /
1,000 ventilation days.

The patients with VAP were statistically more likely to receive treatment with corticosteroids and to require tracheostomy and central vascular catheterization than controls. Univariate analysis also indicated that stay in ICU $\geq$ seven days and ventilation $\geq$ seven days were significantly associated with VAP.

There was no statistically significant difference in hospital mortality among patients with and without VAP (32.1\% vs. $46.5 \%$, respectively. $\mathrm{p}=0.12$ ) as well as when the age was taken in consideration $(47.8 \pm 17.4$ years $v s .48 .2 \pm 18.7$ years, $\mathrm{p}=0.86)$. On the other hand, patients with VAP had a significantly longer duration of mechanical ventilation (23.2 \pm 16.9 days vs. $9.2 \pm 6.7$ days, $\mathrm{p}<0.001)$ compared to patients without VAP.

Multivariate analysis (Table 2) showed that length of MV $(\mathrm{OR}=1.10 ; 95 \% \mathrm{IC}=1.04-1.17 ; \mathrm{p}=0.001)$, mechanical ventilation $=$ seven days $(\mathrm{OR}=7.86 ; 95 \% \mathrm{CI}=1.64-37.61 ; \mathrm{p}=$ $0.01)$, tracheostomy $(\mathrm{OR}=3.09 ; 95 \% \mathrm{CI}=1.28-7.45 ; \mathrm{p}=0.012)$, and use of $\geq 3$ antibiotics $(\mathrm{OR}=4.57 ; 95 \% \mathrm{CI}=2.13-9.82 ; \mathrm{p}<$ $0.001)$ were independent risk factors for the development $\mathrm{O}$ VAP.

The use of antibiotics is shown in Table 3. The univariate analysis of prescription of the several classes showed significant differences in terms of vancomicin use $(\mathrm{OR}=3.337$; $95 \%$ IC $=1.84-6.21 ; \mathrm{p}<0.001)$, fourth generation cephalosporins $(\mathrm{OR}=2.4 ; 95 \% \mathrm{IC}=1.31-4.71 ; \mathrm{p}<0.05)$, aminoglycosides $(\mathrm{OR}=5.32 ; 95 \% \mathrm{IC}=2.49-11.49 ; \mathrm{p}<0.001)$ and carbapenens $(\mathrm{OR}=3.40 ; 95 \% \mathrm{IC}=1.83-6.35 ; \mathrm{p}<0.001)$, besides the use of $\geq 3$ antibiotics of different classes $(\mathrm{OR}=$ $4.25 ; 95 \% \mathrm{IC}=2.22-8.17$; $\mathrm{p}<0.001)$.

The etiological agents of the VAPs are presented in tables 4 and 5. In 62 of the VAPs, one organism was identified, in 16 of the VAPs two different pathogens were found and in only two cases, three agents were recovered. Pseudomonas aeruginosa, (29 cases, 29.0\%), Staphylococcus aureus (28 cases, 28.0\%), Klebsiella-Enterobacter-Serratia group (19 cases, $19.0 \%$ ) and Acinetobacter spp. (18 cases, 18.0\%) were the leading etiologies of VAPs. Infection was monomicrobial in $75.0 \%$ of patients and polymicrobial in $25.0 \%$ of VAPs.

In vitro sensitivity data from both Gram-positive and Gramnegative isolates are shown in Tables 4 and 5. It was found a high rate of multiresistant organisms, with highlight for imipenem-resistant $P$. aeruginosa (52.0\%), oxacillin-resistant S. aureus (65.4\%) and third/fourth generation cephalosporinresistant Klebsiella-Enterobacter-Serratia (43.7\%).

\section{Discussion}

In spite of mechanical ventilation being an essential feature of modern intensive care unit, it is associated with a substantial risk for VAP, which is the most common nosocomial infection in ICU, with an incidence rate ranging from $7 \%$ to more than $40 \%$ [18], and high health care costs [18] besides being the number one cause of death from nosocomial infection in the United States [19,20]. 
Table 1. Risk factors for VAPs in patients under MV interned in adult the ICU of HC-UFU, in the period from March/05 to March/ 06: case-control study

\begin{tabular}{|c|c|c|c|c|c|}
\hline & \multicolumn{2}{|c|}{ Patients } & \multirow[b]{2}{*}{ OR } & \multirow[b]{2}{*}{$95 \% \mathrm{CI}$} & \multirow[b]{2}{*}{ p-value } \\
\hline & $\begin{array}{c}\text { VAP } \\
(n=84)\end{array}$ & $\begin{array}{l}\text { Non-VAP } \\
(n=191)\end{array}$ & & & \\
\hline \multicolumn{6}{|l|}{ Gender } \\
\hline Male & $54(64.2)$ & $117(61.2)$ & 1.14 & $0.65-2.01$ & 0.73 \\
\hline Female & $30(35.8)$ & $74(38.7)$ & 0.88 & $0.50-1.55$ & 0.73 \\
\hline Age (years) & $47.8 \pm 17.4$ & $48.2 \pm 18.7$ & & & 0.86 \\
\hline Age $\geq 70$ years & $11(13.0)$ & $30(15.7)$ & 0.81 & $0.36-1.79$ & 0.47 \\
\hline Hospital stay (days) & $24.7 \pm 16.9$ & $9.2 \pm 6.7$ & & & 0.001 \\
\hline Hospital stay $\geq 7$ days & $83(98.8)$ & $110(57.5)$ & 61.12 & $8.93-1206.4$ & 0.001 \\
\hline \multicolumn{6}{|l|}{ Cause of ICU admission } \\
\hline Clinical & 39 (46.4) & $93(48.6)$ & 0.91 & $0.53-1.58$ & 0.82 \\
\hline Surgical & $19(22.6)$ & $54(28.2)$ & 0.74 & $0.39-1.41$ & 0.40 \\
\hline Trauma & $26(30.9)$ & $44(23.2)$ & 1.50 & $0.81-2.76$ & 0.20 \\
\hline \multicolumn{6}{|l|}{ Comorbidities } \\
\hline Diabetes & $12(14.2)$ & $22(11.5)$ & 1.28 & $0.56-2.89$ & 0.65 \\
\hline COPD & $4(1.1)$ & $12(6.2)$ & 0.75 & $0.20-2.60$ & 0.42 \\
\hline Use of corticoids & $27(32.1)$ & $32(16.7)$ & 2.35 & $1.24-4.45$ & 0.006 \\
\hline Time of MV (days) & $23.2 \pm 17.2$ & $7.6 \pm 5.4$ & & & 0.001 \\
\hline \multicolumn{6}{|l|}{ Invasive procedures } \\
\hline$M V \geq 7$ days & $82(97.6)$ & $87(45.5)$ & 49.01 & $11.40-236.71$ & 0.001 \\
\hline CVC & $82(97.6)$ & $160(83.7)$ & 7.94 & $1.79-49.25$ & 0.002 \\
\hline $\mathrm{VP}$ & $78(92.8)$ & $172(90.0)$ & 1.44 & $0.52-4.20$ & 0.60 \\
\hline Tracheostomy & $50(59.5)$ & $20(10.4)$ & 12.57 & $6.37-25.06$ & 0.001 \\
\hline Total mortality & $27(32.1)$ & 89 (46.5) & 0.63 & $0.36-1.12$ & 0.12 \\
\hline
\end{tabular}

Values are expressed as mean \pm SD and number of patients (\%). VAP - ventilator-associated pneumonia, ICU - intensive care unit, COPD - chronic obstructive pulmonary disease, MV- mechanical ventilation, CVC - central vascular catheter; VP- vesical probe.

Table 2. Multivariate analysis of risk factors for VAPs in patients under MV interned in the adult ICU of HC-UFU, from March/ 05 to $\mathrm{March} / 06$

\begin{tabular}{lcccccc}
\hline & B & SE & Wald $\boldsymbol{\chi}^{2}$ & p value & Exp $(\mathbf{B})$ & 95\% CI of $\operatorname{Exp}(\mathbf{B})$ \\
\hline MV Time & 0.102 & 0.032 & 10.373 & 0.001 & 1.107 & $1.041-1.178$ \\
MV $\geq$ 7 days & 2.063 & 0.798 & 6.680 & 0.010 & 7.869 & $1.646-37.613$ \\
Tracheostomy & 1.128 & 0.449 & 6.309 & 0.012 & 3.091 & $1.281-7.454$ \\
Use $\geq 3$ antibiotics & 1.521 & 0.390 & 15.246 & 0.000 & 4.577 & $2.133-9.822$ \\
Constant & -5.027 & 0.760 & 43.799 & 0.000 & 0.007 & - \\
\hline
\end{tabular}

B: beta; SE: standard error; Wald ${ }^{2}$ : chi-square; df: freedom degree; Exp: exponent; CI: confidence interval.

Table 3. Prescription of antibiotics according to different classes by patient interned in the adult ICU of HC-UFU, in the period from March/05 to March/06

\begin{tabular}{|c|c|c|c|c|c|}
\hline & \multicolumn{2}{|c|}{ Patients } & \multirow[b]{2}{*}{ OR } & \multirow[b]{2}{*}{$95 \% \mathrm{CI}$} & \multirow[b]{2}{*}{ p value } \\
\hline & $\begin{array}{c}\text { VAP } \\
84(\%)\end{array}$ & $\begin{array}{c}\text { Non-VAP } \\
135(\%)\end{array}$ & & & \\
\hline Vancomycin & $54(64.3)$ & $47(34.8)$ & 3.37 & $1.84-6.21$ & 0.001 \\
\hline Penicillins & $39(46.4)$ & $41(30.3)$ & 1.99 & $1.09-3.64$ & 0.02 \\
\hline \multicolumn{6}{|l|}{ Cephalosporins } \\
\hline $3^{\text {rd }} \mathrm{G}$ & $21(25)$ & $41(30.3)$ & 0.76 & $0.39-1.48$ & 0.48 \\
\hline $4^{\text {th }} \mathrm{G}$ & $63(75)$ & $74(54.8)$ & 2.47 & $1.31-4.71$ & 0.004 \\
\hline Aminoglycosides & $32(38.1)$ & $14(10.3)$ & 5.32 & $2.49-11.49$ & 0.001 \\
\hline Carbapenems & $44(65.5)$ & $33(24.4)$ & 3.40 & $1.83-6.35$ & 0.001 \\
\hline Others* & $55(65.5)$ & $71(52.5)$ & 1.71 & $0.94-3.12$ & 0.08 \\
\hline Using $\geq 3$ antibiotics & $64(76.2)$ & $58(42.9)$ & 4.25 & $2.22-8.17$ & 0.001 \\
\hline
\end{tabular}

${ }^{*}$ Clindamycin, ciprofloxacin, levofloxacin, metronidazole, trimethoprim - sulfamethoxazole. 
Table 4. Etiology and resistance of Gram-negative bacteria associated to VAP in patients admitted in the adult ICU of HC-UFU, from March/2005 to March/2006

\begin{tabular}{|c|c|c|c|c|c|c|c|}
\hline \multirow[t]{2}{*}{ Microorganism } & \multirow[b]{2}{*}{$\mathbf{N}(\%)$} & \multicolumn{6}{|c|}{ Antibiotic ${ }^{\#}$} \\
\hline & & IMP & $\mathbf{F U}$ & AMI & CEF & PPT & AMX/CLA \\
\hline Pseudomonas aeruginosa & $29(29)$ & $13 / 25(52)$ & $12 / 24(50)$ & $12 / 23(52.2)$ & $14 / 21 \quad(66.7)$ & $6 / 18(33.3)$ & NT \\
\hline Acinetobacter spp. & $18(18)$ & $2 / 18(11.2)$ & $13 / 16(81.3)$ & $14 / 15(93.3)$ & $14 / 17(82.3)$ & $9 / 15(60)$ & NT \\
\hline Citrobacter freundii & $2(2)$ & $0 / 2(0)$ & $0 / 2(0)$ & $0 / 2(0)$ & $0 / 2(0)$ & NT & $0 / 2(0)$ \\
\hline Enterobacteriaceae $¥$ & $19(19)$ & $2 / 15(13.3)$ & $8 / 14(57.1)$ & $5 / 15(33.3)$ & $7 / 16(43.7)$ & NT & $7 / 12(58.3)$ \\
\hline Burkholderia cepacea & $1(1)$ & 0/1 (0) & 0/1 (0) & $1 / 1(100)$ & $1 / 1(100)$ & $0 / 1(0)$ & NT \\
\hline
\end{tabular}

IMP - imipenem, FLU - fluoroquinolones , AMI - aminoglycosides, CEF $-3^{\text {rd }}$ and $4^{\text {th }}$ generation cephalosporins, PPT - piperacillin + tazobactam , AMX/ CLA - amoxicillin + clavulanic acid. NT - not tested. ${ }^{\#} \mathrm{n}^{\circ}$ of resistant samples $/ \mathrm{n}^{\circ}$ of tested samples (\%). ${ }^{¥}$ Klebsiella spp., Enterobacter spp., Serratia spp.

Table 5. Etiology and resistance of Gram-positive bacteria associated to VAP in patients interned in the adult ICU of HC-UFU, from March/2005 to March/2006

\begin{tabular}{lcccccr}
\hline \multirow{2}{*}{ Microorganism } & & \multicolumn{5}{c}{ Antibiotic $^{\#}$} \\
\cline { 3 - 7 } & $\mathbf{N}(\%)$ & OXA & CLIN & RIF & FU & GU \\
\hline Staphylococcus aureus & $28(28)$ & $17 / 26(65.4)$ & $15 / 25(60)$ & $13 / 24(54.2)$ & $12 / 23(52.2)$ & $0 / 23(0)$ \\
Other Gram +** & $3(3)$ & $2 / 2(100)$ & $1 / 2(50)$ & $1 / 2(50)$ & $0 / 2(0)$ & $0 / 1(0)$ \\
\hline
\end{tabular}

OXA - oxacillin, CLIN - clindamycin, RIF - rifampicin, FLU - fluoroquinolones, GLI - glycopeptides. **S. pneumoniae, S. coagulase. \# $\mathrm{n}^{\circ}$ of resistant samples/ $\mathrm{n}^{\circ}$ of tested samples $(\%)$.

Importantly, VAPs are easier to compare if they are presented as incidence density related with endotracheal tube [21]. The incidence of VAP in our study was high, 24.7 VAPs/ 1,000 ventilator days, considering that rates more commonly range between 10 and 15 cases/1,000ventilator days [22], 13.5 according with NNIS data [23], and were 9.5 and 11.4, 12.7 and 9.4, respectively, episodes per 1.000 device days according to reports of multi-centered studies from Richards et al. (2000)[24], Gastmeier et al.(1997)[25] and Legras et al. (1998)[26] when just clinical-surgical units were analyzed. There are scarce studies assessing VAP importance in Brazil [27]. Recently, Guimarães and Rocco (2006) [28], in an observational study carried out within an ICU of a university hospital in Rio de Janeiro aiming to obtain VAP prevalence, similarly found a high frequency, 35.7 cases $\backslash 1,000$ days of mechanical ventilation.

Although the development of VAP is associated with the same risk factors as other nosocomial infections, there are some predisposing factors that are specific to pulmonary infection [29], mainly endotracheal intubation and mechanical ventilation [30,31]. Risk factors predisposing to VAP are determined in part by the duration of exposure to the ICU environment and the presence of host factors and treatment related factors that predispose to the development of VAP [3], by increasing the likelihood for colonization of the aerodigestive tract with pathogenic bacteria (e.g., prior antibiotic exposure, age $>60$ years, chronic obstructive pulmonary disease) and predisposing to the aspiration of contaminated secretions (e.g., supine positioning, coma, head trauma, etc.) $[3,32]$.

In this study, a multivariate analysis took into account several variables that could be risk factors for VAP and the stepwise logistic regression showed that length of $\mathrm{MV}$, mechanical ventilation $\geq 7$ days, tracheostomy and use of $\geq 3$ antibiotics were independently risk factors for the development of VAP. Otherwise, the univariate analysis showed: duration of MV, length of stay in hospital, steroid treatment, tracheostomy and use of $\geq 3$ antibiotics were significantly associated with VAP cases.

The early and accurate diagnosis of VAP is difficult, but, because of the increasing problem of multiresistant pathogens in many ICUs, it constitutes an urgent challenge as well as a rational basis for an optimal antibiotic treatment. Late onset VAP occurring after four days of hospitalization, as predominant in this study $(79.7 \%)$, are more likely to be caused by multidrug-resistant pathogens associated with increased hospital mortality and morbidity [33-35]. Risk factors for antimicrobial-resistant VAP include besides prior use of antibiotics, prolonged hospitalization, and the presence of invasive devices such as endotracheal tubes and intravascular catheters and inadequate infection control practices [36].

The distribution of identified pathogens was similar to that observed in NNIS system data from 1992 to 1997 and in other studies [37, 38], including high frequencies of $P$. aeruginosa and $S$. aureus. In spite of this, frequencies found of imipenem-resistant $P$. aeruginosa $(52.0 \%)$, oxacillinresistant $S$. aureus (65.4\%), imipenem-resistant $A$. baumannii $(11.0 \%)$ and third/fourth generation cephalosporin-resistant Klebsiella-Enterobacter-Serratia (43.7\%) isolates were high when compared with Latin American and US data [39, 40].

Mortality by VAP remains significant in ICUs [38]; a Brazilian study [41] showed that $50 \%$ of all nosocomial pneumonias are associated with mechanical ventilation, high morbidity, high hospital costs, and high mortality rates [28]. 
In our casuistic mortality was very high (32.1\%), but inferior to that recently reported by Guimarães and Rocco (43\%) [29], however, just like the Rio de Janeiro investigation, mortality rate was not different amongst groups (with and without VAP).

Antibiotic de-escalation, which consists of the initial institution of empirical broad-spectrum antibiotics followed by antibiotic stream lining driven by microbiological documentation, is thought to provide maximum benefit for the individual patient, while reducing the selective pressure for resistance [42]. It should rely on a correct choice of empirical antibiotics, on appropriate microbiological investigation and on a balanced interpretation of microbiological and clinical data $[43,44]$. Results reached by our investigation, such as: VAP high frequencies, use of $\geq 3$ antibiotics, empirical antibiotic therapy, multiresistant bacteria, and mortality rate, suggest the need of a urgent review of nosocomial infection preventive and control measures, as well as the prescription of antibiotics being used in the unit and the evaluation of adopting an antibiotics de-escalonation technique.

In conclusion, VAP poses a therapeutic challenge in an ICU setting. Our observation confirms that treatment for VAP in our institution includes usually $=3$ antibiotics, and that the cases of multiresistant organisms associated and mortality rates are unacceptably high. The practice of de-escalation therapy appears to be urgently needed in order to improve the situation.

\section{Acknowledgements}

The authors thank all those who were directly or indirectly involved in collecting the samples used in this study. We thank Dr. Sérgio Cides for revision of the English text. We are also grateful to Dr. Ednaldo Carvalho Guimarães for statistical assistance.

This study was supported by Conselho Nacional de Desenvolvimento Científico e Tecnológico (CNPq).

\section{References}

1. Vincent J.L., Bihari D.J., Suter P.M., et al. The prevalence of nosocomial infection in intensive care units in Europe: results of the European prevalence of infection in intensive care study. JAMA 1995;247:639-644.

2. Kollef M.H., Vlasnik J., Sharpless L., Pasque C., et al. Scheduled change of antibiotic clases: a strategy to decrease the incidence of ventilator-associated pneumonia. Am J Respir Crit Care Med 1997; $156: 1040-8$.

3. Kollef M.H. Prevention of hospital-associated pneumonia and ventilator-associated pneumonia. Crit Care Med 2004;32:1396405.

4. Kollef M.H. Ventilator-associated pneumonia: a multivariate analysis. JAMA 1993;270:1965-70.

5. George D.L. Epidemiology of nosocomial pneumonia in intensive care unit patients. Clin Chest Med 1995;16:29-44.

6. Fagon J.Y., Chastre J., Hance A.J., et al. Nosocomial pneumonia in ventilated patients: a cohort study evaluating attributable mortality and hospital stay. Am J Med 1993;94:281-8.

7. Bryan C.S., Reynolds K.L. Bacteremic nosocomial pneumonia: analysis of 172 episodes from a single metropolitan area. Am Ver Respir Dis 1984;668-71.
8. Rello J., Gallego M., Mariscl D., et al. The value of routine microbial investigation in ventilador-asociated pneumonia. Am J Respir Care Med 1997:196-200.

9. Alvarez-Lerma F. Modification of empiric antibiotic treatment in patients with pneumonia acquired in the intensive care unit: ICU-acquired pneumonia study group. Intensive Care Med 1996; $55: 2387-394$.

10. Kollef M.H., Ward S. The influence of mini-BAL cultures on patient outcomes: implications for the antibiotic management of ventilator-associated pneumonia in the ICU. Chest 2002;113:112-20.

11. Rello J., Vidaur L., Sandimmenge N., et al. De-escalation therapy in ventilator-associated pneumonia. Crit Care Med 2001;32:28390.

12. Hofken G., Niederman M.S. The importance of a de-escalation strategy for antibiotic treatment of pneumonia in the ICU. Chest 2002;122:2183-96.

13. Kollef M.H. Appropriate empiric antimicrobial therapy of nosocomial pneumonia: the role of the carbapenems. Respir Care 2004; 19:1530-44.

14. Eggimann P., Pittet D. Infection control in the ICU. Chest 2001;120:2059-92.

15. Huskins W.C., O'Rourke E.J., Rhinehart E., Goldmann, D.A. Infection control in countries with limited resources. In: Mayhall, C.G. eds. Hospital Epidemiology and Infection Control. 3 rd.ed. Philadelphia: Lippincott Williams \& Wilkins, 2004.

16. Wey SB. Infection control in a country with annual inflation of 3,600\%. Infect Control Hosp Epidemiol 1995;16(3):175-8.

17. Ayres Júnior M., Ayres D.L., Santos A.S. BioEstat 2.0 : aplicações estatísticas nas áreas das ciências biológicas e médicas. Belém: Sociedade Civil Mamirauá; Brasília: CNPq, 2000.

18. Rello J., Ollendorf D.A., Oster G., et al. Epidemiology and outcomes of ventilator-associated pneumonia in a large US database. Chest 2002;2115-21.

19. Kollef M.H. Ventilator-associated pneumonia. A multivariate analysis. JAMA 1993;270(16):1965-70.

20. Bowton D.L. Nosocomial pneumonia in the ICU-year 2000 and beyond. Chest 1999;115(3 Suppl):28S-33S.

21. Eggimann P., Pittet D. Infection control in the ICU. Chest 2001;120(6):2059-93.

22. Craven D.E. Epidemiology of ventilator-associated pneumonia. Chest 2000;117:185S-7S.

23. National Nosocomial Infections Surveillance (NNIS) System Report, data summary from January 1992 through June 2004, issued October 2004. Am J Infect Control 2004;32(8):470-85.

24. Richards M.J., Edwards J.R., Culver D.H., Gaynes R.P. Nosocomial infections in combined medical-surgical intensive care units in the United States. Infect Control Hosp Epidemiol 2000;21(8):510-5.

25. Gastmeier P., Schumacher M., Daschner F., Ruden H. An analysis of two prevalence surveys of nosocomial infection in German intensive care units. J Hosp Infect 1997;35(2):97-105.

26. Legras A., Malvy D., Quinioux A.I., et al. Nosocomial infections: prospective survey of incidence in five French intensive care units. Intensive Care Med 1998;24(10):1040-6.

27. Carvalho C.R.R. Pneumonia associada à ventilação mecânica $J$ Bras Pneumol 2006;32(4):xx-xxii.

28. Guimarães M.M.Q., Rocco J.R. Prevalência e prognóstico dos pacientes com pneumonia associada à ventilação mecânica em um hospital universitário. J Bras Pneumol 2006;32(4):339-46.

29. Vincent J.L. Nosocomial infections in adult intensive-care units. The Lancet 2003;14:2068-77.

30. Appelgren P., Hellstrom I., Weitzberg E., et al. Risk factors for nosocomial intensive care infection: a long-term prospective analysis. Acta Anaesthesiol Scand 2001;45(6):710-9.

31. Tejada A.A., Bello D.S., Chacon V.E., et al. Risk factors for nosocomial pneumonia in critically ill trauma patients. Crit Care Med 2001;29:304-9. 
32. Cook D.J., Kollef M.H. Risk factors for ICU-acquired pneumonia. JAMA 1998;279:1605-6.

33. Rello J., Ausina V., Ricart M., et al. Impact of previous antimicrobial therapy on the etiology and outcome of ventilator-associated pneumonia. Chest 1993;104(4):1230-5.

34. Kollef M.H., Silver P., Murphy D.M., Trovillion E. The effect of late-onset ventilator-associated pneumonia in determining patient mortality. Chest 1995; $108(6): 1655-62$.

35. Torres A., Aznar R., Gatell J.M., et al. Incidence, risk, and prognosis factors of nosocomial pneumonia in mechanically ventilated patients. Am Rev Respir Dis 1990;142(3):523-8.

36. Kollef M.H., Fraser V.J. Antibiotic resistance in the intensive care unit. Ann Intern Med 2001;134(4):298-314.

37. Richards M.J., Edwards J.R., Culver D.H., et al. Nosocomial infections in medical intensive care units in the United States. Crit Care Med 1999;27:887-92.

38. Kollef M.H, Morrow L.E., Niederman M.S., et al. Clinical characteristics and treatment ventilator-associated pneumonia. Chest 2006; 129:1210-28.

39. Mathai D., Lewis M.T., Kugler K.C., et al. Antibacterial activity of 41 antimicrobials tested against over 2773 bacterial isolates from hospitalized patients with pneumonia: I) results from the
SENTRY Antimicrobial Surveillance Program (North America, 1998). Diagn Microbiol Infect Dis 2001;39(2):105-16. Erratum in: Diagn Microbiol Infect Dis 2001;39(4):275.

40. Sader H.S., Jones R.N., Gales A.C., et al. Antimicrobial susceptibility patterns for pathogens isolated from patients in Latin American medical centers with a diagnosis of pneumonia: analysis of results from the SENTRY Antimicrobial Surveillance Program (1997). SENTRY Latin America Study Group. Diagn Microbiol Infect Dis 1998;32(4):289-301.

41. Prade S.S., Oliveira S.T., Rodrigues R., et al. Estudo brasileiro da magnitude das infecções hospitalares em hospitais terciários. Rev Contr Infec Hosp 1995;2:11-24.

42. Alvares-Lerma F., Alvarez B., Luque P. Empiric broad-spectrum antibiotic therapy of nosocomial pneumonia in the intensive care unit: a prospective observational study. Crit Care Med 2006;10(3):R78.

43. Kollef M.H. Appropriate empiric antimicrobial therapy of nosocomial pneumonia: the role of the carbapenems. Respir. Care 2004; 19 : 1530-44.

44. Rello J., Vidaur L., Sandiumenge A., et al. De-escalation therapy in ventilator-associated pneumonia. Crit Care Med 2004;32(11):2183-90. 